\title{
Breast Cancer in Tunisia: Association of Body Mass Index with Histopathological Aspects of Tumors
}

\author{
Hichem Bouguerra $^{1 \&}$, Hajer Guissouma ${ }^{1 \&}$, Soumaya Labidi ${ }^{2}$, Nejla Stambouli ${ }^{1}$, \\ Raja Marrakchi $^{1}$, Salem Chouaib ${ }^{3}$, Amel Ben Ammar Elgaaied ${ }^{1}$, Hammouda \\ Boussen $^{2}$, Asma Gati ${ }^{1 *}$
}

\begin{abstract}
Background: Previous studies have suggested a link between obesity and breast cancer (BC). However, there is no universal consensus, especially in population based studies. Because only few studies have been conducted on African women, we aimed here to assess the relationship between BMI at time of diagnosis and the BC histopathological features among Tunisian patients according to menopausal status using a hospital-based prospective cohort study. Materials and Methods: Clinical and pathological data were collected from 262 patients stratified on four groups according to their BMI. The relationship between BMI and histopathological features at diagnosis was analysed using univariate and multivariate analysis. Receiver-operating characteristic (ROC) curves were used to evaluate the performance of BMI in predicting of high tumor grade, in comparison to ki-67 index of proliferation. Results: Obesity was correlated with larger tumors, advanced grade and with ER-PRHer2+ BC subtype. An association of BMI with tumor size and tumor grade was observed in both premenopausal and postmenopausal women. Additionally, a significant association between BMI and ER+,ER+PR+Her2+ and ER-PR-Her2+ status was revealed for premenopausal patients, while only ER+PR+Her2+ was associated with BMI for postmenopausal women. Finally, our results showed that compared to Ki67 proliferation index, BMI is a useful prognostic marker of high grade BC tumors. Conclusions: These data are the first to show that in Tunisia obese women suffering from $\mathrm{BC}$ have significantly larger tumors and advanced tumor grade and that higher BMI might influence tumor characteristics and behavior.
\end{abstract}

Keywords: Breast cancer - obesity - body mass index - tumor size - Tunisia

Asian Pac J Cancer Prev, 15 (16), 6805-6810

\section{Introduction}

Breast cancer (BC) is the first female malignancy with 1,38 millions of annual cases worldwide in 2008 and an incidence varying from 18 in Subsaharian Africa to $>90 / 100000$ in occidental countries (Ferlay et al., 2010). In Tunisia, BC represents $25-30 \%$ of all female malignancies, with 2000 annual cases and with an incidence at 30/100000 that doubled during the last 20 years (Missaoui et al., 2011; 2012). Although BC is thought to be a frequent cancer in the developed countries, a majority of all BC deaths occurs in developing world. Infect, increased urbanization and adoption of western lifestyles have augmented $\mathrm{BC}$ rates in the developing countries.

The etiology of BC is not well defined. Several risk factors may be involved on the development of this pathology such as genetic, hormonal, environmental, sociobiological and physiological factors. Many of these risk factors are not reversible, but some, such as obesity, could be modified. Numerous observational studies have investigated the association between obesity and BC (De Pergola and Silvestris, 2013; Minicozzi et al., 2013; Ronco et al., 2012; Sangrajrang et al., 2013 ; Renehan et al., 2008; Majeed et al., 2014; Xing et al., 2014). However, there is no universal consensus on the relationship between BMI and BC, especially in population-based studies. The majority of studies indicating an impact of obesity on BC development have been conducted in Western countries. In our knowledge, so far, only four studies among African women living in Africa have been conducted to estimate a summary measure of the effect of BMI on BC risk (one in Tunisia (Labidi et al., 2008) and three in Nigeria (Adebamowo et al., 2003; Okobia et al., 2006; Ogundiran et al., 2012). Yet, none of these studies have estimated the impact of obesity at diagnostic on histopathological characteristic of BC. In the present study, therefore, we investigate the relationship between $\mathrm{BMI}$ and the prognostic markers of $\mathrm{BC}$ among Tunisian

${ }^{1}$ Laboratoire de Genetique, Immunologie et Pathologies Humaines, Departement de Biologie, Faculte des Sciences de Tunis, CAMPUS, Universite Tunis-El Manar, ${ }^{2}$ Service de carcinologie medicale, Hopital Abderrahman Mami, Ariana, Tunis, Tunisie, ${ }^{3}$ INSERM UMR753, Institut Gustave Roussy, Villejuif, France \&Equal contributors*For correspondence: asmagati@yahoo.fr 
patients according to menopausal status using a hospitalbased retrospective cohort study.

\section{Materials and Methods}

\section{Patients}

This study was conducted in the department of pathology at Department of Medical Oncology, Abderrahman Mami Hospital, Tunis, Tunisia and performed in $262 \mathrm{BC}$ patients. The BC patients were included according to the following criteria: women who (1) had a new histologically confirmed diagnosis of BC; (2) were not treated with radiotherapy, chemotherapy, or anti-estrogens during the previous 6 months; and (3) were not pregnant. The study was approved by the local ethic committee. The ER, PR and HER2 status was centrally reviewed in the pathology department. The histological grade was determined according to the criteria reported by Bloom and Richardson and the tumor size and nodal status were assessed pathologically from surgical specimens. Staining for Ki-67 was performed in the Dako Autostainer Plus automated slide processing system (Dako) with a 1:100 dilution of the monoclonal mouse anti-human Ki67 antibody, clone MIB-1 (DAKO, Glostrup, Denmark). Staining was evaluated by an experienced pathologist without prior knowledge of patient outcome or tumor characteristics The proliferation KI-67 index is considered low or negative, when there are $25 \%$ or less stained nuclei and it is considered positive or high, when there are more than $25 \%$ of stained nuclei.

\section{Statistical analysis}

For the statistical analysis, patients were evaluated according to BMI. Patients with BMI $<25 \mathrm{~kg} / \mathrm{m}^{2}$ were classified as normal weight. Those with BMI between 25 and $29.9 \mathrm{~kg} / \mathrm{m}^{2}$ were classified as overweight, those with BMI between 30 and $34.9 \mathrm{~kg} / \mathrm{m}^{2}$ were classified as obese and those with $\mathrm{BMI} \geq 35$ were classified as severe obese. In this study, the data were analyzed using SPSS software (version 20; SPSS Inc., Chicago, IL, USA). A two-sided p value of $<0.05$ was considered as statistically significant.

Receiver-operating characteristic (ROC) curves were constructed, and the area under the curve (AUC) was calculated to evaluate the performance of BMI as a predictor of tumor grading. An AUC of 1.0 represents error-free prediction of cancer status in all samples, whereas an AUC of 0.50 represents a fifty percent likelihood of a correct prediction of cancer status. The larger the AUC-ROC, the greater is the discriminatory power of the BMI for the outcome.

\section{Results}

The demographic characteristics of breast-cancer patients The mean age of $\mathrm{BC}$ patients was $50.9( \pm 11.9)$ for the entire population. The family history of BC was positive in $85(33.7 \%)$ patients. Patients were divided into four groups based on their BMI; normal weight group consisted of $62(23.6 \%)$ patients, overweight group consisted of 103 $(39.3 \%), 71(27 \%)$ women were in obese group and 26 $(9.9 \%)$ were in severe obese group. Obese women tended to be older at diagnosis of $\mathrm{BC}\left(\chi^{2}=0.097, \mathrm{p}=0.026\right)$ and accounted for a greater percentage of post-menopausal women $(60.8 \%)$ than pre-menopausal women (39.2\%) $(\mathrm{p}=0.025)$. No significant difference in rates of BC family history was seen between the four BMI groups.

\section{Association of BMI with clinicopathologic variables}

We examined the association of the categorical BMI with the clinicopathologic variables at the time of diagnosis. Higher BMI was significantly associated with tumor size $(\mathrm{p}=0.000)$ and with more advanced grade tumors at diagnosis $(\mathrm{p}=0.002)$. Patients had mean baseline BMI of $27.65 \mathrm{~kg} / \mathrm{m}^{2}$ when presenting with stage I disease, $27.8 \mathrm{~kg} / \mathrm{m}^{2}$ with stage II, and $30.011 \mathrm{~kg} / \mathrm{m}^{2}$ with stage III disease. This corresponded to $30 / 73(41.09 \%)$ of patients with baseline $30 \leq \mathrm{BMI}<35 \mathrm{~kg} / \mathrm{m}^{2}$ having stage III at presentation and 15/26 (57.6\%) with baseline BMI $\geq 35$ $\mathrm{kg} / \mathrm{m}^{2}$ compared with only $46 / 159(28.9 \%)$ of patients with $\mathrm{BMI}<30 \mathrm{~kg} / \mathrm{m}^{2}(\mathrm{p}=0.025)$. Among all cases, statistically no significant differences were found in the distribution of pathological characteristics including, ER, PR and Her2 status alone in the BMI groups. Nevertheless, a significant association of BMI with combined ER-PR-HER2+ BC tumors was found $(p=0.021)$. Finally, a signification association of Ki-67 index with BMI was observed $(\mathrm{p}=0.027)$. These results are shown in (Table 1).

\section{Association of tumor features with BMI according to menopausal status \\ The correlations between BMI and tumor features were} evaluated in pre-menopausal and post-menopausal groups (Table 2). Tumor size and grade were correlated with BMI in both groups ( $\mathrm{p}=0.000$ and $\mathrm{p}=0.049$ respectively for premenopausal patients; $\mathrm{p}=0.000$ and $\mathrm{p}=0.011$ respectively for post-menopausal patients). HER-2 and PR were not associated with obesity either in premenopausal or postmenopausal patients. However, ER status has greater relation with obesity in premenopausal cases $(\mathrm{p}=0.004)$. Additionally, among the pre-menopausal cases, we observe a statistically significant association between BMI and the combined ER+PR+Her2+ and ER- PR-Her2+ status ( $p=0.008$ and $p=0.049$ respectively). While, only the combined status ER+PR+Her2+ was significantly associated with BMI in post-menopausal women.

\section{Diagnostic performance of BMI for predicting high BC tumor grade}

We performed ROC curves in order to evaluate the pertinence of the use of BMI as a marker of high tumor grade. The diagnostic capacity of BMI for detection of grade III tumors was compared to the performance of $\mathrm{Ki}-67$ index. As it is shown in Figure 1, the area under curve (AUC) for BMI was 0.66 \pm 0.043 and for Ki-67 was $0.639 \pm 0.046$. A cut-off value of $28.67 \mathrm{~kg} / \mathrm{m}^{2}$ for BMI predicted presence of grade III BC with $61.3 \%$ sensitivity and $63 \%$ specificity. Interestingly, The AUC increases when we consider only BC patients under 40 years of age $(\mathrm{AUC}=0.73 \pm 0.09)$. Finally, the discriminative power of BMI was investigated on BC subtypes according to the menopausal status. These findings are shown in Table 3 . Altogether, these results indicate that BMI is useful as a 
DOI:http://dx.doi.org/10.7314/APJCP.2014.15.16.6805

Breast Cancer in Tunisia: Association of Body Mass Index with Histopathological Aspects

Table 1. Association of BMI with Clinicopathologic Variables

\begin{tabular}{|c|c|c|c|c|c|c|}
\hline & & $\mathrm{BMI}<25$ & $25 \leq \mathrm{BMI}<30$ & $30 \leq \mathrm{BMI}<35$ & $\mathrm{BMI} \geq 35$ & $\mathrm{P}$ value \\
\hline \multirow[t]{4}{*}{ Tumor size } & $<2 \mathrm{~cm}$ & $42(67.7 \%)$ & $29(28.1 \%)$ & $8(11.2 \%)$ & $2(7.6 \%)$ & 0 \\
\hline & $2-5 \mathrm{~cm}$ & $18(29 \%)$ & $55(53.4 \%)$ & $49(69 \%)$ & $16(61.5 \%)$ & \\
\hline & $>5 \mathrm{~cm}$ & $0(0 \%)$ & $13(12.6 \%)$ & $14(19.7 \%)$ & $8(30.7 \%)$ & \\
\hline & Unknown & $2(3.22 \%)$ & $6(5.8 \%)$ & $0 \quad(0 \%)$ & $0 \quad(0 \%)$ & \\
\hline \multirow[t]{4}{*}{ Tumor grade } & Grade I & $6 \quad(9.6 \%)$ & $11(10.5 \%)$ & $8(10.9 \%)$ & $0 \quad(0 \%)$ & 0 \\
\hline & Grade II & $38(61.2 \%)$ & $58(55.7 \%)$ & $35(47.9 \%)$ & $11(42.3 \%)$ & \\
\hline & Grade III & $15(24.1 \%)$ & $31(29.8 \%)$ & $30(41.09 \%)$ & $15(57.6 \%)$ & \\
\hline & Unknown & $3(4.8 \%)$ & $3(2.8 \%)$ & $0 \quad(0 \%)$ & $0 \quad(0 \%)$ & \\
\hline \multirow[t]{3}{*}{ Lymph node metasis } & No & $48(81.3 \%)$ & $83(79.8 \%)$ & $55(75.3 \%)$ & $19(73 \%)$ & 0.12 \\
\hline & Yes & $5(8.4 \%)$ & $10(9.6 \%)$ & $9(12.3 \%)$ & $5(19.2 \%)$ & \\
\hline & Unkown & $6(10.1 \%)$ & $11(10.5 \%)$ & $9(12.3 \%)$ & $2(7.6 \%)$ & \\
\hline \multicolumn{7}{|l|}{ Expression of tumor marker } \\
\hline \multirow[t]{3}{*}{ ER status } & Positive & $39(66.1 \%)$ & $62(59.6 \%)$ & $42(57.5 \%)$ & $13(50 \%)$ & 0.05 \\
\hline & Negative & $15(25.4 \%)$ & $35(33.6 \%)$ & $26(35.7 \%)$ & $12(46.1 \%)$ & \\
\hline & Unknown & $5(8.4 \%)$ & $7(6.7 \%)$ & $5(6.8 \%)$ & $1(3.8 \%)$ & \\
\hline \multirow[t]{3}{*}{ PR status } & Positive & $34(57.62 \%)$ & $57(54.8 \%)$ & $38(52 \%)$ & $13(50 \%)$ & 0.27 \\
\hline & Negative & $21(35.5 \%)$ & $38(36.5 \%)$ & $28(38.3 \%)$ & $12(46.1 \%)$ & \\
\hline & Unknown & $4(6.7 \%)$ & $9(8.6 \%)$ & $(9.58 \%)$ & $1(3.8 \%)$ & \\
\hline \multirow[t]{3}{*}{ Her2 status } & Positive & $30(50.8 \%)$ & $55(52.8 \%)$ & $42(57.5 \%)$ & $17(65.3 \%)$ & 0.33 \\
\hline & Negative & $22(37.2 \%)$ & $44(42.3 \%)$ & $27(36.9 \%)$ & $8(30.7 \%)$ & \\
\hline & Unknown & $7(11.8 \%)$ & $5(4.8 \%)$ & $4(5.4 \%)$ & $1(3.8 \%)$ & \\
\hline \multirow[t]{4}{*}{ ER/PR satus } & $\mathrm{ER}+/ \mathrm{PR}+$ & $34(24.5 \%)$ & $55(39.5 \%)$ & $38(27.5 \%)$ & $12(8.6 \%)$ & 0.18 \\
\hline & ER+/PR- & $5(35.7 \%)$ & $5(35.7 \%)$ & $3(21.4 \%)$ & $1(7.1 \%)$ & 0.24 \\
\hline & ER-/PR+ & $0 \quad(0 \%)$ & $2(66.7 \%)$ & $0 \quad(0 \%)$ & $1(33.3 \%)$ & 0.43 \\
\hline & ER-/PR- & $15(17.9 \%)$ & $33(39.3 \%)$ & $25(29.8 \%)$ & $11(13.1 \%)$ & 0.08 \\
\hline \multirow[t]{8}{*}{ ER/PR/Her2 status } & ER+/Her2- & $18(29.5 \%)$ & $20(32.8 \%)$ & $17(27.9 \%)$ & $6(9.8 \%)$ & 0.37 \\
\hline & PR+/Her2- & $15(26.8 \%)$ & $19(33.9 \%)$ & $17(30.4 \%)$ & $5 \quad(8.9 \%)$ & 0.5 \\
\hline & $\mathrm{ER}+/ \mathrm{Her} 2+$ & $20(21.7 \%)$ & $41(44.6 \%)$ & $24(26.1 \%)$ & $7 \quad(7.6 \%)$ & 0.36 \\
\hline & PR+/Her2+ & $18(21.4 \%)$ & $37(44 \%)$ & $21(25 \%)$ & $8(9 \%)$ & 0.77 \\
\hline & $\mathrm{ER}+/ \mathrm{PR}+/$ Her2- & $15(25.4 \%)$ & $17(16.3 \%)$ & $17(23.2 \%)$ & $5(19.2 \%)$ & 0.47 \\
\hline & $\mathrm{ER}+/ \mathrm{PR}+/$ Her $2+$ & $18(30.5 \%)$ & $37(35.5 \%)$ & $21(28.7 \%)$ & $7(26.9 \%)$ & 0.51 \\
\hline & ER-/PR-/Her2+ & $9(15.2 \%)$ & $13(12.5 \%)$ & $17(23.2 \%)$ & $9(34.6 \%)$ & 0.02 \\
\hline & ER-PR-Her2- & $4(6.7 \%)$ & $19(18.2 \%)$ & $8(10.9 \%)$ & $2(7.6 \%)$ & 0.97 \\
\hline \multirow[t]{3}{*}{ Ki-67 Proliferation Index } & Low & $22(37.2)$ & $36(34.6 \%)$ & $21(25.3 \%)$ & $4 \quad(4.8 \%)$ & 0.02 \\
\hline & High & $12(20.3 \%)$ & $39(37.5 \%)$ & $16(21.9 \%)$ & $12(46.1 \%)$ & \\
\hline & Unknown & $25(42.3 \%)$ & $29(27.8 \%)$ & $36(49.3 \%)$ & $10(38.4 \%)$ & \\
\hline
\end{tabular}

Table 2. Tumor Features Correlation with BMI according to the Menopausal Status

\begin{tabular}{|c|c|c|c|c|c|c|c|c|c|c|}
\hline & \multicolumn{5}{|c|}{ Premenopausal $(\mathrm{N}=121)$} & \multicolumn{5}{|c|}{ Postmenauposal $(\mathrm{N}=141)$} \\
\hline & $\mathrm{BMI}<25$ & $25 \leq \mathrm{BMI}<30$ & $30 \leq \mathrm{BMI}<35$ & $\mathrm{BMI} \geq 35$ & $\mathrm{p}$ value & $\mathrm{BMI}<25$ & $25 \leq \mathrm{BMI}<30$ & $30 \leq \mathrm{BMI}<35$ & $\mathrm{BMI} \geq 35 \mathrm{p}$ & $\mathrm{p}$ value \\
\hline Patients (\%) & $36(29.8 \%)$ & $47(38.8 \%)$ & $27(22.3 \%)$ & $11(9.1 \%)$ & & $23(16.3 \%)$ & $57(40.4 \%)$ & $46(32.6 \%)$ & $15(10.6 \%)$ & \\
\hline \multicolumn{11}{|l|}{ Tumor size } \\
\hline$<2 \mathrm{~cm}$ & $23(63.8 \%)$ & $13(27.6 \%)$ & $4(14.8 \%)$ & $0 \quad(0 \%)$ & 0.00 & $17(73.91 \%)$ & $18(31.5 \%)$ & $3(6.5 \%)$ & $2(13.3 \%)$ & 0.000 \\
\hline $2-5 \mathrm{~cm}$ & $13(36.1 \%)$ & $21(44.6 \%)$ & $13(48.1 \%)$ & $4(36.3 \%)$ & & $4(17.3 \%)$ & $30(52.6 \%)$ & $34(73.9 \%)$ & $8(53.3 \%)$ & \\
\hline$>5 \mathrm{~cm}$ & $0 \quad(0 \%)$ & $10(21.2 \%)$ & $9(33.3 \%)$ & $7(63.6 \%)$ & & 0 & $6(10.5 \%)$ & $9(19.5 \%)$ & $5(33.3 \%)$ & \\
\hline Unknown & $0 \quad(0 \%)$ & $0 \quad(0 \%)$ & $1 \quad(3.7 \%)$ & $0 \quad(0 \%)$ & & $2(8.6 \%)$ & $3(5.2 \%)$ & $0 \quad(0 \%)$ & $0 \quad(0 \%)$ & \\
\hline \multicolumn{11}{|l|}{ Tumor grade } \\
\hline Grade I & $4(11.1 \%)$ & $3(6.3 \%)$ & $5(18.5 \%)$ & $0 \quad(0 \%)$ & 0.04 & $2(8.6 \%)$ & $8(14.0 \%)$ & $3(6.5 \%)$ & $0 \quad(0 \%)$ & 0.01 \\
\hline Grade II & $21(58.3 \%)$ & $31(65.9 \%)$ & $12(44.4 \%)$ & $4(36.3 \%)$ & & $17(73.9 \%)$ & $27(47.3 \%)$ & $23(50 \%)$ & $7(46.6 \%)$ & \\
\hline Grade III & $11(30.5)$ & $12(25.5 \%)$ & $10(37 \%)$ & $7(63.6 \%)$ & & $4(17.3 \%)$ & $19(33.3 \%)$ & $20(43.4 \%)$ & $8(53.3 \%)$ & \\
\hline Unknown & $0 \quad(0 \%)$ & $0 \quad(0 \%)$ & $0 \quad(0 \%)$ & $0 \quad(0 \%)$ & & $0 \quad(0 \%)$ & $3(5.2 \%)$ & $0 \quad(0 \%)$ & $0 \quad(0 \%)$ & \\
\hline \multicolumn{11}{|c|}{ Lymph node metasis } \\
\hline No & $30(83.3 \%)$ & $38(80.85 \%)$ & $21(77.77 \%)$ & $9(81.81 \%)$ & 0.61 & $18(78.2 \%)$ & $45(78.9 \%)$ & $34(73.9 \%)$ & $10(66.6 \%)$ & 0.1 \\
\hline Yes & $2(5.55 \%)$ & $6(12.7 \%)$ & $2(7.4 \%)$ & $1(9 \%)$ & & $3(13 \%)$ & $4(7 \%)$ & $7(15.2 \%)$ & $4(26.6 \%)$ & \\
\hline Unkown & $4(11.11 \%)$ & $3(6.38 \%)$ & $4(14.8 \%)$ & $1(9 \%)$ & & $2(8.6 \%)$ & $8(14 \%)$ & $5(10.8 \%)$ & $1(6.6 \%)$ & \\
\hline \multicolumn{11}{|l|}{ ER status } \\
\hline Positive & $28(77.7 \%)$ & $33(70.2 \%)$ & $16(59.2 \%)$ & $5(45.4 \%)$ & 0.004 & $11(47.8 \%)$ & $29(50.8 \%)$ & $26(56.5 \%)$ & $8(53.3 \%)$ & 0.68 \\
\hline Negative & $5(13.8 \%)$ & $11(23.4 \%)$ & $7(25.9 \%)$ & $6(54.5 \%)$ & & $10(43.4 \%)$ & $24(42.1 \%)$ & $19(41.3 \%)$ & $6(40 \%)$ & \\
\hline Unknown & $3(8.3 \%)$ & $3(6.3 \%)$ & $4(14.8 \%)$ & $0 \quad(0 \%)$ & & $2(8.6 \%)$ & $4(7 \%)$ & $1(2.1 \%)$ & $1(6.6 \%)$ & \\
\hline \multicolumn{11}{|l|}{ PR status } \\
\hline Positive & $26(72.2 \%)$ & $33(70.2 \%)$ & $15(55.5 \%)$ & $5(45.4 \%)$ & 0.05 & $8(34.7 \%)$ & $24(42.1 \%)$ & $23(50 \%)$ & $8(53.3 \%)$ & 0.21 \\
\hline Negative & $8(22.2 \%)$ & $11(23.4 \%)$ & $7(25.9 \%)$ & $6(54.5 \%)$ & & $13(56.5 \%)$ & $27(47.3 \%)$ & $21(45.6 \%)$ & $6(40 \%)$ & \\
\hline Unknown & $2(5.55 \%)$ & $3(6.3 \%)$ & $5(18.5 \%)$ & $0 \quad(0 \%)$ & & $2(8.6 \%)$ & $6(10.5 \%)$ & $2(4.3 \%)$ & $1 \quad(6.66 \%)$ & \\
\hline \multicolumn{11}{|l|}{ Her2 status } \\
\hline Positive & $20(55.5 \%)$ & $28(59.5 \%)$ & $14(51.8 \%)$ & $8(72.7 \%)$ & 0.69 & $10(43.4 \%)$ & $27(47.3 \%)$ & $28(60.8 \%)$ & $9(60 \%)$ & 0.23 \\
\hline Negative & $13(36.1 \%)$ & $18(38.2 \%)$ & $11(40.7 \%)$ & $3(27.2 \%)$ & & $9(39.1 \%)$ & $26(45.6 \%)$ & $16(34.7 \%)$ & $5(33.3 \%)$ & \\
\hline Unknown & $3(8.33 \%)$ & $1(2.1 \%)$ & $2(7.4 \%)$ & $0 \quad(0 \%)$ & & $4(17.3 \%)$ & $4 \quad(7 \%)$ & $2(4.3 \%)$ & $1 \quad(6.66 \%)$ & \\
\hline \multicolumn{11}{|l|}{ Tumor markers } \\
\hline ER+/PR+/Her2- & $11(30.5 \%)$ & $8(17 \%)$ & $8(29.6 \%)$ & $2(18.1 \%)$ & 0.07 & $4(17.3 \%)$ & $9(15.7 \%)$ & $9(19.5 \%)$ & $3(20 \%)$ & 0.34 \\
\hline $\mathrm{ER}+/ \mathrm{PR}+/$ Her $2+$ & $14(38.8 \%)$ & $23(48.9 \%)$ & $7(25.9 \%)$ & $218.1 \%)$ & 0.01 & $4(17.3 \%)$ & $14(24.5 \%)$ & $14(30.4 \%)$ & $5(33.3 \%)$ & 0.08 \\
\hline ER-/PR-/Her2+ & $3(8.33 \%)$ & $5(10.6 \%)$ & $5(18.5 \%)$ & $5(45.4 \%)$ & 0.03 & $6(26 \%)$ & $8(14 \%)$ & $12(16 \%)$ & $4(26.6 \%)$ & 0.24 \\
\hline ER-PR-Her2- & $2(5.55 \%)$ & $5(10.6 \%)$ & $1 \quad(3.7 \%)$ & $3(27.2 \%)$ & 0.68 & $2(8.6 \%)$ & $14(24.5 \%)$ & $7(15.2 \%)$ & $2(13.3 \%)$ & 0.76 \\
\hline
\end{tabular}




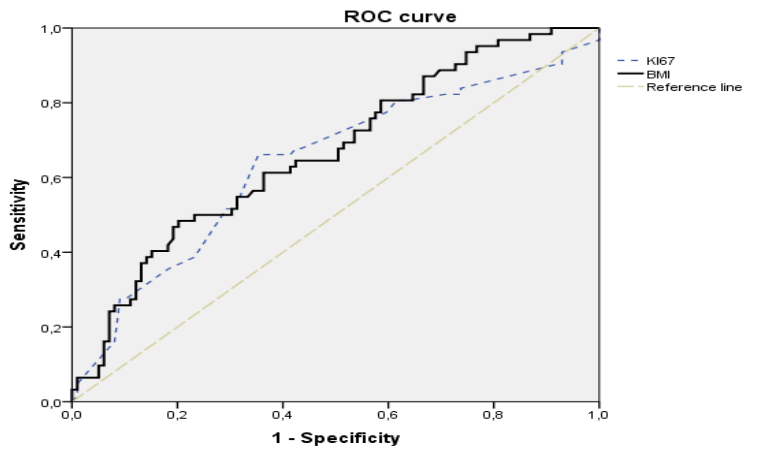

Figure 1. Receiver Operating Characteristic Curves using BMI and Ki-67 to Predict Grade III BC

Table 3. The Predicting Ability of BMI among BC Subtypes and according to Menopausal Status

\begin{tabular}{lcll}
\hline & & AUC $(95 \%$ CI $)$ & \\
& \multicolumn{1}{c}{ Total } & Premenopausal & Postmenopausal \\
\hline ER+ & $0.59(0.49-0.69)$ & $0.56(0.43-0.70)$ & $0.63(0.49-0.76)$ \\
ER- & $0.62(0.49-0.74)$ & $0.66(0.43-0.89)$ & $0.60(0.45-0.74)$ \\
PR+ & $0.56(0.46-0.66)$ & $0.53(0.40-0.67)$ & $0.59(0.44-0.74)$ \\
PR- & $0.64(0.53-0.75)$ & $0.68(0.46-0.9)$ & $0.62(0.49-0.76)$ \\
Her2+ & $0.59(0.49-0.68)$ & $0.53(0.38-0.68)$ & $0.64(0.51-0.77)$ \\
Her2- & $0.64(0.53-0.76)$ & $0.73(0.57-0.89)$ & $0.57(0.41-0.73)$ \\
ER+PR+Her2- & $0.58(0.41-0.75)$ & $0.70(0.50-0.90)$ & $0.46(0.19-0.74)$ \\
ER+PR+Her2+ & $0.57(0.44-0.70)$ & $0.48(0.31-0.66)$ & $0.66(0.48-0.84)$ \\
ER-PR-Her2+ & $0.60(0.44-0.77)$ & $0.67(0.39-0.95)$ & $0.56(0.35-0.78)$ \\
ER-PR-Her2- & $0.64(0.44-0.84)$ & $0.58(0-1)$ & $0.63(0.41-0.86)$ \\
\hline
\end{tabular}

specific marker to predict grade III BC.

\section{Discussion}

$\mathrm{BC}$ is one of the most prevalent malignancies in women around the world (Jemal et al., 2011). The average age of occurrence of the $\mathrm{BC}$ in Tunisia reveals that the disease occurs a decade earlier, as compared with the Western countries (Chouchane et al., 2013). In the present study, mean age of cases was $50.9 \pm 11.9$. By contrast, the average age of occurrence of BC among US white womens has been reported to be 61.0 years (Chouchane et al., 2013). The continuing rise of $\mathrm{BC}$ incidence has created an urgent need to develop strategies for its prevention. One of the few modifiable risk factors that may affect BC development is obesity (Amadou et al., 2013; Yaw et al., 2014). The prevalence of obesity has augmented in parallel to cancer, reaching epidemic proportions in many countries. In Tunisia, obesity is frequent among older women; its incidence is about $33.5 \%$ among all women and about $52.1 \%$ of women over 45 years (Belfki et al., 2013; Maatoug et al., 2013). Several studies have investigated the relationship between BC and obesity, yet the results have been mixed among ethnic groups (Amadou et al., 2013).

In this study, we investigated 262 Tunisian patients to evaluate the effect of BMI on pathological features of BC. Our results revealed that obesity is associated with larger tumor size and higher tumor grade in both premenopausal and postmenopausal women. These findings are consistent with studies conducted on African American (Zhu et al., 2005), Danish (Ewertz et al., 2011), Iranian (Kaviani et al., 2013) and Asian women (Amadou et al., 2013). However, an inverse association between BMI and $\mathrm{BC}$ risk, with a $7 \%$ reduction in risk per $5 \mathrm{~kg} \mathrm{~m}^{-2}$ increase in BMI was documented in premenopausal Caucasians womens (Renehan et al., 2008; Amadou et al., 2013). The variation observed between the ethnic groups may be explained by differences in body size and fat composition in different populations. Indeed, a study on the relationship between BMI and body fat in different population, revealed that Asian are different from Caucasians populations, this can be partly explained by differences in body build, i.e. differences in trunk-to-leg-length ratio or differences in slenderness (Deurenberg et al., 2002).

Additionally, our results revealed that lymph node metastasis are not more common in obese women compared to normal weight women. This observation was in accordance with the study conducted by Keskin and al (Keskin et al., 2013). Nevertheless, the association between obesity and higher risk of lymph node metastasis was reported by other groups (Porter et al., 2006; Singh et al., 2011; Kaviani et al., 2013).

The status of ER and PR in obese women was also a matter of controversy. Several studies conducted to evaluate the effect of BMI at time of diagnostic on histopathological features concluded that obese postmenopausal women develop more frequently ER/PR positive tumors (Biglia et al., 2013). However, others studies showed that obesity and overweight increases the risk of developing triple negative BC subtype, particularly for premenopausal women (Turkoz et al., 2013). Our results revealed that there is an association between BMI and ER-PR-Her2+ tumor subtype. Interestingly, when the data are stratified according to the menopausal status, a significant association of BMI with combined $\mathrm{ER}+\mathrm{PR}+\mathrm{Her} 2+$, ER-PR-Her2+ and ER+ BC tumors was observed for premenopausal women, whereas only $\mathrm{ER}+\mathrm{PR}+\mathrm{Her} 2+$ subtype is associated with BMI among postmenopausal patients. As the association between BMI and expression of ER and PR is a matter of controversy in literature, further studies must be conducted using large $\mathrm{BC}$ registry database to determine the impact of obesity on these important prognosis factors.

ROC curve analysis was used to determine the discriminative power of BMI, in comparison to Ki-67 proliferation index, to predict aggressive tumors at time of diagnostic (Kilickap et al., 2014). Our results demonstrate that $\mathrm{BMI}$ is as pertinent as $\mathrm{Ki}-67$ in predicting high tumor grade. Hence, obesity could be considered as a reliable marker for agressive BC. The same observation was reported by other groups (Hajian-Tilaki et al., 2011). Recently, Santillan-Benitez et al have demonstrate that BMI, leptin, leptin/adiponectin ratio and CA 15-3 together are reliable biomarkers of BC (Santillan-Benitez et al., 2013). These findings imply to perform BC screening program in women with a higher BMI.

The mechanism by which obesity influences BC remains poorly understood. Several possible mechanisms have been suggested: $i$ ) Obese people often have increased levels of insulin and insulin-like growth factor-1 in their blood, which may promote the development of tumors (Belardi et al.,2013), ii) Adipose tissue produces hormones, called adipokines such as leptine and adiponectine, that 
may stimulate angiogenesis, growth of malignant cells (Grossmann et al., 2010; Khan et al., 2013) and that may modulate anti-tumor immune response (Catalan et al., 2013) iii) Finally, obesity is associated with elevated levels of pro-inflammatory cytokines (Harvey et al., 2011) which generate a low grade chronic inflammatory state that may be involved on cancer development (Hanahan and Weinberg, 2011; Ferguson et al., 2013).

In conclusion, our results revealed that obesity is associated with larger tumor size and higher tumor grade and that BMI can be useful for predicting high grade tumors. As the prevalence of obesity in the world continues to raise, improvement in detection strategies, specific treatments and diet interventions are needed.

\section{Acknowledgements}

This work is supported by CMCU grant 13G0819.

\section{References}

Adebamowo CA, Ogundiran TO, Adenipekun AA, et al (2003). Obesity and height in urban Nigerian women with breast cancer. Ann Epidemiol, 13, 455-61.

Amadou A, Ferrari P, Muwonge R, et al (2013). Overweight, obesity and risk of premenopausal breast cancer according to ethnicity: a systematic review and dose-response metaanalysis. Obes Rev, 14, 665-78.

Belardi V, Gallagher EJ, Novosyadlyy R, et al (2013). Insulin and IGFs in obesity-related breast cancer. J Mammary Gland Biol Neoplasia, 18, 277-89.

Belfki H, Ben Ali S, Aounallah-Skhiri H, et al (2013). Prevalence and determinants of the metabolic syndrome among Tunisian adults: results of the Transition and Health Impact in North Africa (TAHINA) project. Public Health Nutr, 16, 582-90.

Biglia N, Peano E, Sgandurra P, et al (2013). Body mass index (BMI) and breast cancer: impact on tumor histopathologic features, cancer subtypes and recurrence rate in pre and postmenopausal women. Gynecol Endocrinol, 29, 263-7.

Catalan V, Gomez-Ambrosi J, Rodriguez A, et al (2013). Adipose tissue immunity and cancer. Front Physiol, 4, 275.

Chouchane L, Boussen H, and Sastry KS (2013). Breast cancer in Arab populations: molecular characteristics and disease management implications. Lancet Oncol, 14, 417-24.

De Pergola G, and Silvestris F (2013). Obesity as a major risk factor for cancer. J Obes, 2013, 291546.

Deurenberg P, Deurenberg-Yap M, and Guricci S (2002). Asians are different from caucasians and from each other in their body mass index/body fat per cent relationship. Obes Rev, 3, 141-6.

Ewertz M, Jensen MB, Gunnarsdottir KA, et al (2011). Effect of obesity on prognosis after early-stage breast cancer. $J$ Clin Oncol, 29, 25-31.

Ferguson RD, Gallagher EJ, Scheinman EJ, et al (2013). The epidemiology and molecular mechanisms linking obesity, diabetes, and cancer. Vitam Horm, 93, 51-98.

Ferlay J, Shin HR, Bray F, et al (2010). Estimates of worldwide burden of cancer in 2008: GLOBOCAN 2008. Int J Cancer, 127, 2893-917.

Grossmann ME, Ray A, Nkhata KJ, et al (2010). Obesity and breast cancer: status of leptin and adiponectin in pathological processes. Cancer Metastasis Rev, 29, 641-53.

Hajian-Tilaki KO, Gholizadehpasha AR, Bozorgzadeh S, et al (2011). Body mass index and waist circumference are predictor biomarkers of breast cancer risk in Iranian women. Med Oncol, 28, 1296-301.
Hanahan D, Weinberg RA (2011). Hallmarks of cancer: the next generation. Cell, 144, 646-674.

Harvey AE, Lashinger LM, and Hursting SD (2011). The growing challenge of obesity and cancer: an inflammatory issue. Ann N Y Acad Sci, 1229, 45-52.

Jemal A, Bray F, Center MM, et al (2011). Global cancer statistics. CA Cancer J Clin, 61, 69-90.

Kaviani A, Neishaboury M, Mohammadzadeh N, et al (2013). Effects of obesity on presentation of breast cancer, lymph node metastasis and patient survival: a retrospective review. Asian Pac J Cancer Prev, 14, 2225-9.

Keskin O, Aksoy S, Babacan T, et al (2013). Impact of the obesity on lymph node status in operable breast cancer patients. $J$ BUON, 18, 824-30.

Khan S, Shukla S, Sinha S, et al (2013). Role of adipokines and cytokines in obesity-associated breast cancer: therapeutic targets. Cytokine Growth Factor Rev, 24, 503-13.

Kilickap S, Kaya Y, Yucel B, et al (2014). Higher Ki67 expression is associates with unfavorable prognostic factors and shorter survival in breast cancer. Asian Pac J Cancer Prev, 15, 1381-5.

Labidi SI, Mrad K, Mezlini A, et al (2008). Inflammatory breast cancer in Tunisia in the era of multimodality therapy. Ann Oncol, 19, 473-80.

Maatoug J, Harrabi I, Hmad S, et al (2013). Advising obese adults about diet and physical activity in Sousse, Tunisia. ISRN Obes, 2013, 498527.

Majeed W, Aslam B, Javed I, et al (2014). Breast cancer: major risk factors and recent developments in treatment. Asian Pac J Cancer Prev, 15, 3353-8.

Minicozzi P, Berrino F, Sebastiani F, et al (2013). High fasting blood glucose and obesity significantly and independently increase risk of breast cancer death in hormone receptorpositive disease. Eur J Cancer, 49, 3881-8.

Missaoui N, Jaidene L, Abdelkrim SB, et al (2011). Breast cancer in Tunisia: clinical and pathological findings. Asian Pac J Cancer Prev, 12, 169-72.

Missaoui N, Landolsi H, Jaidaine L, et al (2012). Breast cancer in central Tunisia: an earlier age at diagnosis and incidence increase over a 15 -year period. Breast J, 18, 289-91.

Ogundiran TO, Huo D, Adenipekun A, et al (2012). Body fat distribution and breast cancer risk: findings from the Nigerian breast cancer study. Cancer Causes Control, 23, 565-74.

Okobia MN, Bunker CH,Zmuda JM, et al (2006). Anthropometry and breast cancer risk in Nigerian women. Breast $J, \mathbf{1 2}$, 462-6.

Porter GA, Inglis KM, Wood LA, et al (2006). Effect of obesity on presentation of breast cancer. Ann Surg Oncol, 13, 327-32.

Renehan AG, Tyson M, Egger M, et al (2008). Body-mass index and incidence of cancer: a systematic review and meta-analysis of prospective observational studies. Lancet, 371, 569-78.

Ronco AL, De Stefani E, Deneo-Pellegrini H, et al (2012). Diabetes, overweight and risk of postmenopausal breast cancer: a case-control study in Uruguay. Asian Pac J Cancer Prev, 13, 139-46.

Sangrajrang S, Chaiwerawattana A, Ploysawang P, et al (2013). Obesity, diet and physical inactivity and risk of breast cancer in Thai women. Asian Pac J Cancer Prev, 14, 7023-7.

Santillan-Benitez JG, Mendieta-Zeron H, Gomez-Olivan LM, et al (2013). The tetrad BMI, leptin, leptin/adiponectin (L/A) ratio and CA 15-3 are reliable biomarkers of breast cancer. J Clin Lab Anal, 27, 12-20.

Singh AK, Pandey A, Tewari M, et al (2011). Obesity augmented breast cancer risk: a potential risk factor for Indian women. J Surg Oncol, 103, 217-22. 
Bouguerra Hichem et al

Turkoz FP, Solak M, Petekkaya I, et al (2013). Association between common risk factors and molecular subtypes in breast cancer patients. Breast, 22, 344-50.

Xing MY, Xu SZ, and Shen P (2014). Effect of low-fat diet on breast cancer survival: a meta-analysis. Asian Pac J Cancer Prev, 15, 1141-4.

Yaw YH, Shariff ZM, Kandiah M, et al (2014). Diet and physical activity in relation to weight change among breast cancer patients. Asian Pac J Cancer Prev, 15, 39-44.

Zhu K, Caulfield J, Hunter S, et al (2005). Body mass index and breast cancer risk in African American women. Ann Epidemiol, 15, 123-8. 